\title{
Um panorama da produçáo jornalística audiovisual no ciberespaço: as experiências das redes colaborativas*
}

\section{RESUMO}

A convergência midiática e a interatividade têm sido incorporadas às rotinas produtivas do jornalismo na internet, porém não têm garantido a qualidade dos textos. O trabalho consiste numa reflexão crítica sobre os modos de utilização da linguagem audiovisual e os processos interativos oferecidos por sites jornalísticos e redes colaborativas. A partir de um mapeamento dessas experiências e de uma análise comparativa das redes Overmundo e Canal Contemporâneo, e dos portais UOL e G1, são apontadas possibilidades de construção de novos formatos e conteúdos audiovisuais no ciberespaço e modos diferentes de produção e consumo de informações jornalísticas. O estudo revela que essas redes podem se constituir em práticas inovadoras de jornalismo.

\section{PALAVRAS-CHAVE}

tecnologias digitais

narrativas jornalísticas audiovisuais

redes colaborativas

\section{ABSTRACT}

The media convergence and interactivity has been incorporated into journalism routine production in Internet, but do not have guaranteed the quality of texts. The work is a critical reflection on how to use the audiovisual language and about the interactive processes offered by news sites and collaborative networks. From a mapping of those experiences and a comparative analysis of networks Overmundo and Canal Contemporâneo, and portals UOL and G1, are aimed possibilities of construction of new formats and audiovisual contents in cyberspace and new ways of production and consumption news. The study reveals that such networks are able to be constituted in innovative practices of journalism.

\section{KEY WORDS}

digital technologies

audiovisual journalistic narratives

collaborative networks

\section{Beatriz Becker}

Professora do Programa de Pós-Graduação em Comunicação da UFRJ/RJ/BR beatrizbecker@uol.com.br

\section{Juliana Teixeira}

Mestranda do Programa de Pós-Graduação em Jornalismo da UFSC/SC/BR julianafernandesri@yahoo.com.br
No século XX, o desenvolvimento dos meios de comunicação aceleraram a circulação de notícias, constituindo um fluxo contínuo de informação em escala internacional. Nas últimas décadas os conteúdos jornalísticos regionais, nacionais e internacionais ganharam espaço expressivo na imprensa escrita, nas emissoras de rádio e, especialmente, na televisão. A partir dos anos 90, a internet passou a provocar profundas alterações nas rotinas produtivas do jornalismo. Há, porém, uma ilusão referente a uma espécie de plenitude informativa da contemporaneidade, sustentada pela "sensação" de estar informado, como explica Sodré (2001, p. 60), pelo fato de estar "quase-presente" ao acontecimento veiculado pela imagem e pela retórica repetitiva, simplificadora e veloz das mensagens, e não por conteúdos jornalísticos pertinentes à compreensão da realidade histórica.

O processo de produção da notícia resulta da cultura profissional, dos processos produtivos, dos critérios de noticiabilidade e dos valores-notícia (Traquina, 2005) e dos códigos e regras particulares do campo da comunicação. Deve ser compreendido como um trabalho de construção de discursos sobre os fatos transformados em acontecimentos (Pena, 2005, p.128), que servem à formação da opinião pública. Os ângulos determinados na produção das reportagens com seus diferentes enquadramentos buscam conferir significados à realidade cotidiana, às relações sociais e às instituições. A função da mídia de organizar e hierarquizar a realidade nos relatos dos acontecimentos ocorre de forma mais expressiva e impactante quando se faz uso da linguagem audiovisual, um campo da comunicação complexo na construção e ressignificação de sentidos (Vizeu, 2008, p. 7-14). Às narrativas jornalísticas audiovisuais, tanto na TV quanto na internet, nos referimos como práticas de jornalismo audiovisual, cuja qualidade pressupõe as representações dos fatos diversidade de atores sociais, pluralidade de interpretações, inovações estéticas e contextualização dos acontecimentos, o que o uso da convergência, necessariamente, não garante.

Há muitas críticas e indagações sobre a exploração dos novos formatos informativos e sobre o grau de inovação dos sites jornalísticos na apuração e no tratamento das notícias. Segundo Salaverría (2005, p. 520) frente ao mito, se apresenta uma modesta realidade porque o hipertexto raramente é utilizado como recurso narrativo no ciberespaço. Apesar de todos os avanços tecnológicos, a imprensa online ainda busca uma identidade própria. Em pesquisas anteriores (Becker; Teixeira, 2008), identificamos que as webtvs, 
webjornalismo audiovisual caracterizada por projetos editoriais de informação e entretenimento produzidos e dirigidos exclusivamente para a internet.

Os sites audiovisuais que produzem conteúdos exclusivos para o meio digital ainda experimentam os primeiros passos em direção a uma gramática própria, que carecem da experimentação de novas formas de narrativa com aproveitamento de recursos multimídia e de interatividade, capazes de proporcionar ao usuário a oportunidade de navegar e percorrer um relato noticioso mais do que simplesmente acompanhálo de modo linear. Nesse trabalho investigamos se a utilização da linguagem audiovisual na construção de novos conteúdos e nos processos interativos disponibilizados pelos sites jornalísticos mais acessados no país e pelas redes colaborativas pode colaborar para outras representações das realidades sociais cotidianas.

Realizamos um mapeamento de distintas experiências que incorporam esses processos na web, questionando o potencial das novas tecnologias de informação para descentralização da produção jornalística, para a criação de novos formatos e conteúdos e, consequentemente, para a promoção de percepções mais amplas das realidades do Brasil e do mundo. Nessa investigação, as reflexões sobre os efeitos das novas tecnologias nas práticas sócioculturais foram amparadas pelas teorias do jornalismo e pela Análise Crítica do Discurso. Os estudos de interações mediadas por computador e da linguagem audiovisual também foram relevantes para investigar com maior profundidade o objeto de estudo da investigação proposta.

\section{Os sites audiovisuais que} produzem conteúdos exclusivos para 0 meio digital ainda experimentam os primeiros passos em direção a uma gramática própria, que carecem da experimentação de novas formas de narrativa com aproveitamento de recursos multimídia e de interatividade

Utilizamos como metodologia a análise comparativa quantitativa e qualitativa, constituída a partir de categorias que nos permitem observar as características e o funcionamento de cada um dos sites e redes analisados. Em acordo com Albornoz (2007, p. 54), observamos que diferentes experiências informativas no ciberespaço são analisadas, a partir da "hipertextualidade", uma forma multidirecional, não linear, de estruturar e acessar informações numa plataforma digital promovendo relações com outros dados, através de links; da "interatividade", um conceito que remete à idéia de que os membros da audiência podem iniciar e desenvolver ações plenas de comunicação tanto com o meio quanto com outros usuários, o que de modo geral, não ocorre de modo efetivo; e da "multimidialidade", que supõe a possibilidade de integrar em um mesmo suporte diferentes formatos e linguagens. A qualidade dos conteúdos informativos, como explica Salaverría (2005, p. 517), não depende do uso da hipertextualidade, da interatividade e da multimidialidade. Um conteúdo de um site jornalístico pode ser excelente sem recorrer a essas posibilidades, até porque um texto com infinidades de recursos pode carecer de valor informativo. Mas, essas características narrativas das notícias no ciberespaço apresentam novas possibilidades de construção discursivas que devem ser avaliadas e exploradas. Por essa razão, consideramos estes critérios nessa análise comparativa e ainda acrescentamos outras três categorias inspiradas também nos trabalhos de Nogueira (2005) e Palácios (2002) : a "estrutura", para que possamos indicar como o conteúdo é sistematizado através de determinadas estratégias de usabilidade; a "atualidade", para observarmos a peridiocidade e velocidade de produção e circulação da informação, característica inenerente à atividade jornalística; e a "memória", a capacidade de armazenamento de dados no ambiente digital, através de sistemas de busca.

\section{Desafios do jornalismo digital}

Os dados referentes à expansão do mercado digital são contundentes. A internet ainda tem uma participação pequena frente a outros meios no bolo publicitário no país, mas foi a mídia que mais cresceu em termos percentuais em 2008. Durante o primeiro trimestre deste ano, a internet ficou com uma fatia de $3,24 \%$ desse mercado, um crescimento de $36 \%$ em relação ao ano anterior ${ }^{1}$, reunindo $\mathrm{R} \$ 134,3$ milhões em investimentos. O número de pessoas com acesso à internet no Brasil já ultrapassou 40 milhões de pessoas, 22,5\% de uma população de 184 milhões de habitantes acessam a $w e b^{2}$. E o brasileiro ainda passou a ser o internauta que mais horas navega na internet por mês em todo o mundo, $23 \mathrm{~h} 48 \mathrm{~min}^{3}$. Embora os números de internautas venham crescendo bastante nos últimos anos, o contingente de analfabetos digitais ainda responde por mais da metade de todos os brasileiros. Segundo Castells (2003, p. 138), a Internet é de fato 
uma tecnologia da liberdade, mas pode libertar os poderosos para oprimir os desinformados e levar à exclusão dos desvalorizados pelos conquistadores do valor. A batalha pela liberdade na Era da Informação está sendo disputada na rede e o poder é exercido em torno da produção e difusão de nós culturais e conteúdos de informação.

As novas tecnologias tendem a ampliar o status quo e os poderes político-financeiros, mas seguem diferentes tendências de desenvolvimento, usos e significados de acordo com distintos contextos sócio-culturais. Observamos que os modos de utilização da internet pelos brasileiros carecem de estudos mais específicos. Uma pesquisa recente ${ }^{4}$, porém, indica que a maioria expressiva dos usuários, $88 \%$ dos brasileiros, busca na internet notícias diariamente. Nesse contexto, os sites jornalísticos passam a ocupar lugares estratégicos. Esses dados tornam-se ainda mais expressivos se considerarmos a desaceleração constante da venda de jornais diários em relação aos anos anteriores ${ }^{5}$. A tiragem diária do jornal mais vendido no país, a Folha de São Paulo é de pouco mais de 300 mil exemplares por dia ${ }^{6}$. Outro estudo revela que $98 \%$ dos jovens assistem à TV 3,4 horas por dia, embora esse veículo venha caindo na preferência dos jovens e a internet esteja subindo. Para os jovens das classes A e B, a internet leva vantagem sobre a TV: $43 \%$ a $26 \%$. Na classe C a realidade é outra: a TV tem $33 \%$ da preferência e a web $21 \%$. Nas classes D e E, são $42 \%$ para a TV e só $10 \%$ para a rede ${ }^{7}$.

Este panorama obriga os diários online a esforçarse por ofertar uma bateria de conteúdos e serviços capazes de atrair a atenção do público. Observamos, porém, que os sites mais acessados ${ }^{8}$ pertencem a grandes grupos de mídia e as decisões destas empresas têm grande poder de influência nos conteúdos e na gestão da circulação da informação. Os sites jornalísticos contam com recursos suficientes para inserí-los numa posição de vanguarda e inovação técnica no mercado, por outro lado, são alimentados por conteúdos de outras empresas dos grupos de mídia a que pertencem, o que prejudica a diversidade e a pluralidade de interpretações, o investimento em conteúdos mais consistentes e na inventividade estética, e, consequentemente, em um jornalismo de maior qualidade (Becker, 2008). De qualquer modo, já é possível identificar mudanças na forma das narrativas audiovisuais. A imagem fixa tem ocupado cada vez mais espaço, como na imprensa escrita, e a presença de áudio e de imagens em movimento, e mais timidamente de arquivos multimídia tem sido fortalecida.

Por essas razões, uma análise das apropriações da linguagem audiovisual e dos processos de interação proporcionados pelos sites jornalísticos e pelas redes colaborativas, é uma contribuição importante para fomentar o acesso coletivo e gratuito aos conteúdos e serviços distintos disponibilizadosnarede, estimulando a produção e postagem de diferentes temas, abordagens e formatos de notícias, capazes de sustentar relações comerciais e industriais, mas também de gerar novas formas de produção e consumo de informação jornalística e de representar mútiplas identidades culturais e maior pluralidade de interpretações dos acontecimentos sociais. Observamos até que ponto a conexão, a convergência e a interatividade são utilizadas para desenvolver narrativas jornalísticas audiovisuais de maior qualidade, investigando ainda se os processos interativos proporcionados pelos sites jornalísticos e pelas redes colaborativas contribuem para a construção de uma sociedade mais democrática e descentralizada.

\section{Redes colaborativas}

A experiência das redes colaborativas é um exemplo das formas contemporâneas de apropriação das novas tecnologias para o estabelecimento de outros tipos de mediações sócio-culturais. Segundo Castells (1999), as redes são sistemas organizacionais capazes de reunir indivíduos e instituições, de forma voluntária e democrática, em torno de objetivos e/ou temáticas comuns, e são estabelecidas por relações horizontais que supõem o trabalho colaborativo e participativo.

\section{0 processo de constituição das redes colaborativas pressupõe a superação de interesses corporativistas, da tradição hierárquica e clientelista que ainda marcam as relações sociais}

Algumas vezes, as redes colaborativas utilizam esse potencial na luta social, assumindo, desse modo, a característica de espaços que atuam ativamente na promoção de mudanças, afetando até mesmo os processos produtivos, o poder e a cultura, constituindose como fontes potenciais de transformação da sociedade. Mas, o processo de constituição das redes colaborativas pressupõe a superação de interesses corporativistas, da tradição hierárquica e clientelista que ainda marcam as relações sociais. Nesse sentido, na produção jornalística, as redes permitem que as informações sejam compartilhadas por todos, sem canais reservados, favorecendo a formação de uma cultura de comunicação efetiva que fortaleça, ao mesmo tempo, a autonomia e a participação dos cidadãos, o que não significa que todo cidadão estaria automaticamente exercendo o jornalismo. 
Kunczik; Varela (1997, p. 16) definem o jornalismo como a profissão das pessoas que reúnem, avaliam, difundem ou comentam as notícias. $O$ jornalista seria o profissional envolvido na formulação de conteúdos analíticos para a comunicação de massa, seja na apuração, na apreciação, no processamento ou na divulgação de informações. Portanto, embora as informações de redes colaborativas, que funcionam como plataformas de microblogging sejam rapidamente reproduzidas nas emissoras de TV e websites de mídia, muitos cidadãos estariam apenas acessando ou utilizando as ferramentas disponíveis para postagem de conteúdos, até porque, como mostra Aguiar', fotos de um incêndio, de um massacre ou de um fenômeno ambiental agregam valor de consumo imediato, mas não de conhecimento. Informações transmitidas por essas redes carecem de atributos interpretativos, de tratamentos diferenciados dos fatos sociais, que valorizam mais a notícia como mercadoria do que como forma de conhecimento de realidades sociais. Além disso, se 135 milhões de usuários, ou seja, $60 \%$ da população brasileira, já tem acesso a comunicação móvel ${ }^{10}$, isso não significa que todo este percentual de brasileiros esteja distribuído em todo território nacional, participe das redes colaborativas, tenha acesso e habilidade com os equipamentos e programas de transmissão de dados, e tampouco tenha formação profissional adequada para investigar um fato da maneira mais ampla possível, o que restringe a publicação de novos conteúdos audiovisuais.

Assumimos, portanto, como hipótese que a descentralização na produção de conteúdos audiovisuais não garante a qualidade das notícias publicadas, nem a incorporação das possibilidades do hipertexto, mas novas apropriações da linguagem audiovisual e dos recursos multimídia podem colaborar para a promoção de um jornalismo de qualidade. E as redes colaborativas oferecem possibilidades de produção de novos conteúdos noticiosos audiovisuais marcados pela diversidade.

\section{Produção colaborativa audiovisual no ciberespaço}

Realizamos, primeiramente, um mapeamento de nove experiências brasileiras realizadas atualmente no ciberespaço que aproveitam a contribuição do usuário e que apresentam propostas diferentes do uso da linguagem audiovisual e de recursos multimídia e estruturas narrativas singulares para realizar a nossa investigação, em acordo com os critérios da originalidade, da diversidade e da representatividade, sugeridos pelo Grupo de Jornalismo Online da UFBA - GJOL. O site Overmundo ${ }^{11}$ representa uma iniciativa de jornalismo cidadão e se propõe a ser um canal de expressão da produção cultural do Brasil sustentado por recursos do governo federal. $\mathrm{O}$ Canal Contemporâneo ${ }^{12}$ é um exemplo de jornalismo segmentado, relacionado especificamente à cultura.
Define-se como uma comunidade digital que procura discutir a arte, seus circuitos e políticas públicas.

O Observatório de Imprensa ${ }^{13}$ foi escolhido porque é a primeira experiência de crítica de mídia na web produzida no país, tornando-se o primeiro site brasileiro a ter uma versão televisiva. É uma iniciativa do Laboratório de Estudos Avançados em Jornalismo da Unicamp que se constitui como um fórum permanente de debates. Estudamos também o uso da linguagem audiovisual e dos recursos de multimídia, assim como os processos interativos do $\mathrm{UOL}^{14} \mathrm{e}$ do $\mathrm{G}^{15}$ , os sites jornalísticos mais acessados no Brasil ${ }^{16}$. Estes sites também foram selecionados porque a TVUOL, inserida no portal, é a primeira experiência de webtv no país e o G1 concentra a maior porcentagem de usuários de banda larga. Vc no G1 ${ }^{17}$ é a editoria dedicada a receber e disponibilizar as contribuições dos usuários, que podem ser textos, fotos ou vídeos. O Leia Livro ${ }^{18}$ foi escolhido como exemplo de sites temáticos. Essa rede colaborativa da Secretaria de Estado da Cultura de São Paulo foi desenvolvida para promover o hábito da leitura.

\section{Apesar de todos os avanços tecnológicos, a imprensa online e as redes colaborativas ainda carecem de publicações de conteúdos mais analíticos, da exploração de novos formatos e de um maior aproveitamento da convergência
possibilitada pela rede}

Pudemos reconhecer, ainda, algumas experiências importantes na produção de conteúdos colaborativas para a web no Fórum de Mídia Livre realizado na Escola de Comunicação da UFRJ em 2008. A TV Lata ${ }^{19}$ é um projeto realizado pela ONG Bagunçaço em Salvador, com a participação de crianças e jovens entre 8 e 19 anos, que têm autonomia para escolher os temas referentes à comunidade, gravar e publicar vídeos. $\mathrm{O}$ projeto do Instituto Espaço $\mathrm{Cubo}^{20}$ foi iniciado em Cuiabá, com foco na cena da música independente, viabilizando a realização de trabalhos, através de uma forma alternativa de captar recursos, a troca de força de trabalho contabilizada na forma de moeda cultural. E o Canal Motoboy ${ }^{21}$ é uma webtv, cujas imagens são gravadas e editadas por motoboys que retratam 
em vídeos e fotos tirados de câmeras de celulares o cotidiano da cidade de São Paulo e dos profissionais do trânsito paulistano.

Os primeiros resultados desse estudo indicaram que apesar de todos os avanços tecnológicos, a imprensa online e as redes colaborativas ainda carecem de publicações de conteúdos mais analíticos, da exploração de novos formatos e de um maior aproveitamento da convergência possibilitada pela rede. A maioria dos conteúdos informativos é escrito. Os sites jornalísticos estão submetidos a uma linha editorial que, de modo geral, privilegia a reprodução e o aproveitamento de conteúdos previamente elaborados para os veículos impressos ou pelas emissoras de televisão que pertencem a um mesmo grupo de mídia. E as redes colaborativas revelam pouca habilidade no tratamento dos recursos audiovisuais e de multimídia. Constatamos que a maioria das peças formadas por arquivos digitais de áudio e vídeo não são produzidas exclusivamente para a rede. São utilizadas estruturas narrativas bastante simples, sem fazer uso do hipertexto para manter a concisão descritiva do texto principal e permitir, ao mesmo tempo, que o usuário amplie voluntariamente por meio de hiperlinks, informações sobre uma pessoa mencionada, sobre os lugares em que ocorreram os acontecimentos e sobre diferentes pontos de vistas dos atores sociais envolvidos em determinado fato social.

\section{Uma análise comparativa}

Interessadas em aprofundar nossa investigação sobre os potenciais das redes colaborativas para a promoção de um jornalismo de qualidade e sobre os processos de interação oferecidos pelos sites jornalísticos mais acessados no Brasil para descentralização da produção jornalística, estabelecemos seis diferentes categorias para realizar uma análise comparativa qualitativa e quantitativa de quatro portais informativos, dois sites jornalísticos e duas redes colaborativas, selecionados entre as nove experiências anteriormente mapeadas, que procuram promover interatividade no tratamento das notícias e utilizam a linguagem audiovisual e recursos multimídia na publicação de conteúdos: o Overmundo, o Canal Contemporâneo, a TV UOL, a seção do UOL dedicada a vídeos, e o Vc no G1, a editoria do G1 aberta à participação dos usuários. As categorias já referidas - hipertextualidade, interatividade, multimidialidade, estrutura, atualidade, e memória foram adotadas para nos permitir alcançar os objetivos propostos. Essa investigação foi realizada em setembro e em outubro de 2008. Aplicamos as categorias descritas na análise comparativa.

Observamos que os softwares utilizados permitem a postagem de textos escritos, imagens fixas, áudio e vídeo. Os dois últimos formatos não são usados com a mesma frequência que os demais nas colaborações dos usuários. As imagens fixas, especialmente as fotos, são usadas para destacar as chamadas da homepage ou para complementar as informações escritas. Os infográficos são visíveis apenas nas reportagens anteriormente produzidas por emissoras de televisão e publicadas nos sites jornalísticos. Nenhuma reportagem audiovisual enviada pelos usuários emprega este recurso nos sites estudados durante o período analisado. Os ícones de TVs e rádios para identificar reportagens em vídeo e áudio favorecem a navegabilidade, porém são utilizados somente nos portais UOL e G1.

Todos os sites analisados oferecem a oportunidade de publicação de conteúdos de áudio e vídeo. Mas, no Canal Contemporâneo foram encontrados em média apenas dois vídeos artísticos apresentados na homepage por dia num total de 21 textos informativos, 15 no formato jornalístico. $\mathrm{Na}$ homepage do Overmundo também é possível acessar em média dois vídeos, registros curtos de imagens de acontecimentos presenciados pelos usuários sem características narrativas de reportagens, inseridos nos 13 assuntos destacados na página principal, seis trabalhados como notícias na forma escrita. Matérias jornalísticas em áudio e vídeo são verificadas somente nos portais UOL e G1, mas todas seguem o formato telejornalístico e a duração das notícias varia de 30 segundos a 3 minutos.

A perspectiva do usuário como agente no processo de comunicação subverte a forma de distribuição unilateral e a recepção passiva de informações nas redes colaborativas, e aponta para uma nova maneira de pensar a relação entre produtores e consumidores, entre jornalistas e cidadãos, entre os veículos de comunicação e a sociedade

A produção jornalística audiovisual corresponde a $8 \%$ do conteúdo do UOL. Na homepage do portal 40 dos 50 destaques, ou seja, $80 \%$ são dedicados ao jornalismo, e apenas três são chamadas para matérias que utilizam a linguagem audiovisual. Das 19 chamadas publicadas diariamente na primeira página da TV UOL, $49 \%$ são vídeos de entretenimento e $51 \%$ são jornalísticos, a maior parte produzida pelo UOL. 
O percentual da produção jornalística audiovisual no G1 é praticamente o mesmo do UOL, $9 \%$, embora o site tenha em média um número maior de chamadas. 55 de 65 destaques se referem a notícias diversas, mas é possível acessar apenas cinco reportagens que combinam som, imagem em movimento e recursos multimídia disponibilizadas por meio de links na página principal.

A editoria Vc no G1 apresenta em média 18\% das suas chamadas na homepage com links para conteúdos audiovisuais por dia, $66 \%$ são jornalísticos, e a maioria é produzida pela Rede Globo. Os vídeos publicados pelos usuários na TV UOL e no Vc no G1 são comparativamente mais numerosos e têm maior atualidade do que nas redes colaborativas, as quais procuram manter uma periodicidade mais dinâmica através de boletins informativos e de programações culturais. Tanto na TV UOL quanto no Vc no G1, porém, a maior parte dos textos audiovisuais colaborativos são clips musicais, traillers de filmes e curiosidades ou registros de acontecimentos sem estrutura de narrativa jornalística.

Os resultados dessa investigação revelam que há uma escassez de recursos audiovisuais e multimídia e dispositivos ainda restritos de participação de usuários mais livres e ativos disponibilizados. Nesse sentido, a contextualização e a diversidade de representações dos fatos sociais não são, consequentemente, inerentes ao jornalismo audiovisual do futuro, uma vez que as mesmas mensagens circulam em suportes diferentes, supostamente neutros, ainda reduzindo o lugar do usuário ao consumo, sem o estabelecimento de uma relação simétrica entre produção e recepção (Primo, 2007, p. 17-54). As redes e sites analisados são projetos abertos, já que recebem colaborações de qualquer usuário. $\mathrm{O}$ envio das contribuições, porém, nem sempre garante a publicação dos conteúdos enviados porque os textos são selecionados pelos editores.

\section{Considerações Finais}

O desenvolvimento da tecnologia e a evolução dos modos de transmissão e compressão de dados estimulam o incremento da produção e da publicação de vídeos na internet, podendo proporcionar outros significados e sentidos sobre a experiência social cotidiana. Isso não quer dizer que a produção descentralizada possa enfrentar com facilidade os domínios de grandes monopólios de comunicação. Os efeitos das novas tecnologias nas rotinas produtivas do jornalismo, assim como em todos os sitemas de mercado geram desigualdades. Os custos para um site manter uma conexão de banda larga, com capacidade de armazenar e disponibilizar conteúdos audiovisuais, e para um internauta produzir textos de qualidade em áudio e vídeo ainda são muito altos. A concentração do mercado dificulta a entrada de produtores de conteúdo menos favorecidos economicamente, o que colabora para a ausência da pluralidade de pontos de vista e da inovação estética nas construções discursivas. É preciso superar a falta de recursos não apenas com criatividade e capacidade de partilhar conteúdos, mas também adotando processadores baratos de distribuição e armazenamento de informações, especialmente na cadeia produtiva do audiovisual digital. Desse modo, há possibilidades de sistemas dinâmicos de uso livre serem apropriados e modalidades inovadoras de jornalismo serem desenvolvidas no ciberespaço, mesmo em condições precárias de infra-estrutura tecnológica. As redes colaborativas podem, efetivamente, se constituir como uma experiência inovadora de produção jornalística. A perspectiva do usuário como agente no processo de comunicação subverte a forma de distribuição unilateral e a recepção passiva de informações nas redes colaborativas, e aponta para uma nova maneira de pensar a relação entre produtores e consumidores, entre jornalistas e cidadãos, entre os veículos de comunicação e a sociedade. Sugerimos que a inserção de novos sujeitos na produção da mídia gera mudanças estéticas e nas linguagens, pode promover diferentes modos de contar histórias do cotidiano, e demanda outros estudos para identificar essas transformações $\square$ FAMEcos

\section{NOTAS}

* Trabalho apresentado no GT Estudos de Jornalismo do XVIII Encontro Anual da Compós 2009.

1 www1.folha.uol.com.br/folha/informatica/ult124u416776.shtml

2 www1.folha.uol.com.br/folha/informatica/ult124u416776.shtml

3 www1.folha.uol.com.br/folha/informatica/ult124u416776.shtml

4 josemauronunes.wordpress.com/2009/01/09/acesso-a-internet-no-brasil-cresce-a-passos-largos/

5 www.midialogismo.com/2009/01/tiragem-dosjornais-pagos-cresce-5-no.html

6 www.midialogismo.com/2009/01/tiragem-dosjornais-pagos-cresce-5-no.html

7 www1.folha.uol.com.br/folha/informatica/ult124u426874.shtml.

8 www.alexa.com

9 www.observatoriodaimprensa.com.br/artigos. asp?cod=522ENO001.

10 Dados do Ministério das Comunicações anunciados na palestra de Jefferson Fued Nacif, especialista em Políticas Públicas e Gestão Governamental, no V Fórum Internacional de TV Digital.

11 www.overmundo.com.br

12 www.canalcontemporaneo.art.br

13 www.observatoriodaimprensa.com.br

14 vuol.uol.com.br

15 g1.globo.com

16 www.alexa.com 
17 g1.globo.com

18 www.leialivro.com.br

19 www.tvlata.org

20 www.cubocard.blogspot.com

21 www.zexe.net/SAOPAULO

\section{REFERÊNCIAS}

AGUIAR, Pedro. $O$ "jornalismo twitter" não muda nada. http:/ / www.observatoriodaimprensa. com.br/artigos.asp?cod=522ENO001. Acessado em janeiro de 2009.

ALBORNOZ, Luis A. Periodismo digital: Los grandes diários em la Red. Buenos Aires: La Crujía, 2007.

BECKER, Beatriz. Diversidade e pluralidade: Desafios da Produção de um telejornalismo de qualidade. In: BORGES, Gabriela; REIABAPTISTA, (orgs.). Discursos e Práticas de Qualidade na Televisão. Lisboa: Novos Horizontes, p. 357-367, 2008.

BECKER, Beatriz; TEIXEIRA, Juliana. Webjornalismo Audiovisual: Perspectivas para um Jornalismo de Qualidade no Ciberespaço. Revista do NP de Comunicação Audiovisual da Intercom, São Paulo, v.1, n.2, p. 97-113, 2008.

BIANCONI, Giulliana. Meninos mais novos já preferem internet à TV no Brasil. http:/ / www1.folha.uol.com.br/folha/ informatica/ult124u426874.shtml. Acessado em novembro de 2008.

CASTELLS, Manuel. A sociedade em rede: a era da informação: economia, sociedade e cultura. São Paulo: Paz e Terra, 1999.

. A Galáxia da internet. Rio de Janeiro: Jorge Zahar Editor, 2003.

ESSENFELDER, Renato. Tiragem dos jornais pagos cresce 5\% no Brasil, mas média é enganadora. http://www.midialogismo.com/2009/01/ tiragem-dos-jornais-pagos-cresce-5-no.html. Acessado em janeiro de 2009.

FAIRCLOUGH, Norman. Discurso e mudança social. Brasília: UNB, 2001.

FOLHA ON LINE. Internet no Brasil chega a mais de 40 milhões de pessoas. http://www1. folha.uol.com.br/folha/informatica/ ult124u416776.shtml. 2008. Acessado em novembro de 2008.
IT WEB. 41 milhões têm acesso à internet no Brasil. http://www.itweb.com.br/noticias/index. asp?cod=49199. Acessado em novembro de 2008.

KUNCZIK, Michael; VARELA JR., Rafael. Conceitos de jornalismo: norte e sul - Manual de comunicação. São Paulo: EdUSP, 1997.

MACHADO, Arlindo. Arte e mídia. Rio de Janeiro: Jorge Zahar, 2007.

MACHADO, Elias. O Ensino de jornalismo em tempos de ciberespaço. In: MACHADO, Elias e PALÁCIOS, Marcos (Orgs.). O Ensino do jornalismo em redes de alta velocidade. Salvador: EDUFBA, p.11-21, 2007.

NUNES, José Mauro. Acesso à internet no Brasil cresce a passos largos. http:/ /josemauronunes.wordpress. com/2009/01/09/acesso-a-internet-no-brasilcresce-a-passos-largos. 2009. Acessado em janeiro de 2009.

PALACIOS, Marcos. Jornalismo online, informação e memória: Apontamentos para debate. http:// www.facom.ufba.br/jol/pdf/2002_palacios_ informacaomemoria.pdf. Acessado em 10 de abril de 2008.

PRIMO, Alex. Interação mediada por computador. Porto Alegre: Sulina, 2007.

SALAVERRÍA, Ramón. Hipertexto periodístico: mito y realidad. En: Masip, Pere; Josep Rom (Eds.). La utopia digital en els mitjans de comunicació: dels discursos als fets. Un balanç. Barcelona: Universitat Ramon Llull, 2005.

SODRÉ, Muniz. Antropológica do espelho - uma teoria da comunicação linear e em rede. Petrópolis, RJ: Vozes, 2001.

TRAQUINA, Nelson. Teorias do jornalismo, Vol. II. Florianópolis: Insular, 2005.

VIZEU, Alfredo (Org.). A sociedade do telejornalismo. Petrópolis: Vozes, 2008. 